\title{
Aortic valve replacement in a case of Ehlers Danlos syndrome
}

\author{
PHILIP EDMONDSON, MAURICE NELLEN, AND DONALD N. ROSS
}

From The Cardiac Unit, The Harley Street Clinic, 35 Weymouth Street, London

SUMmary A case of Ehlers Danlos syndrome is described in a 54-year-old Caucasian male. He had calcific aortic valve disease and dilatation of the ascending aorta. An aortic valve replacement was performed using a Starr prosthesis.

The rare inheritable disease of connective tissuethe Ehlers Danlos syndrome-was first described in 1682 by the Dutch surgeon Job Van Meekeren (McKusick, 1972). Since that time much has been learned of the wide spectrum of the condition, and 7 distinct types of the disease have been separated on clinical, genetic, and biochemical grounds (McKusick, 1974).

The different types have varying degrees of skin hyperextensibility, easy bruising, and abnormally mobile joints. Inheritance is variable, but specific patterns occur in several types, in some of which definite biochemical abnormalities can be found (Pinnell et al., 1972; Lichtenstein et al., 1973; Sussman et al., 1974; Di Ferrante et al., 1975; Pope et al., 1975).

Surgery has always presented a problem in the Ehlers Danlos syndrome because incisions tend to widen spontaneously, sutures may tear out, and there is often great difficulty in haemostasis. The degree of risk varies between the types, and cardiac surgery has only been attempted on rare occasions. Fantl et al. (1961) described the repair of a partial, persistent, atrioventricular canal and clefts in the tricuspid and mitral valves in a boy of 11 with only mild features of the syndrome, and Frieden $e t$ al. (1962) reported a patient who died after an operation to repair ruptured aortic valve cusps.

We report the successful replacement of a stenotic aortic valve by a Starr-Edwards prosthesis in a patient with type II Ehlers Danlos syndrome, a mild classic form of the disorder.

\section{Case report}

The patient was a 54-year-old Caucasian male executive who presented for a routine health examination. He had been noted to bruise and scar excessively after minor injuries in childhood, and to have hyperextensible joints, but the condition had never worried him and he had served in the army with the Chindits.

His mother had characteristic features of Ehlers Danlos syndrome, his brother had the disease and had 2 affected children, but his sister was normal. The patient's adult medical history was relatively uneventful, though 3 years previously he had been found to have glaucoma, which was treated medically, and he had also developed a hydrocele. $\mathrm{He}$ had no symptoms related to the heart or cardiovascular system, and he led an active life.

On physical examination he measured 5 feet 10 inches, weighed $153 \mathrm{lb}(69.40 \mathrm{~kg})$, and had a normal physique. There were no features suggestive

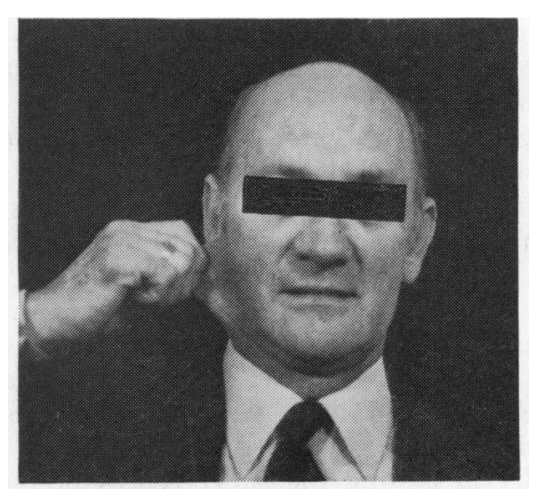

Fig. The skin of the patient's neck is unduly easily stretched. 
of Marfan's syndrome. The skin of his forehead was deeply puckered, his ears were hyperextensible, and there were redundant folds of skin on his knees and elbows with ecchymoses and characteristic papyracious scars but no pseudotumours were evident. In general his skin had a soft velvety texture and it was excessively stretchable but not lax (Fig.). The joints of his fingers could be bent backwards but the larger joints were normal. The heart was enlarged and a soft thrill was palpable in the aortic area. The first and second heart sounds were soft, and a harsh, short, aortic, ejection systolic murmur followed by a soft early diastolic murmur was audible. The electrocardiogram showed high voltage over the left ventricle with deeply inverted $T$ waves. Chest $x$-ray film showed an enlarged left ventricle and dilatation of the ascending aorta.

During the course of the next few months after diagnosis the patient remained free of symptoms, but his electrocardiogram deteriorated and began to show deeper ST segment depression and $\mathrm{T}$ wave inversion in the left chest leads. Surgical replacement of the aortic valve was advised.

Aortography was performed successfully via the right brachial artery. The vessel was delivered easily but stretched abnormally. It took sutures satisfactorily, with patency of the lumen afterwards and a good radial pulse.

At operation through a midsternal incision the left ventricle was hypertrophied and the ascending aorta showed features of post-stenotic dilatation with a narrow aortic root and expansion approximately $4 \mathrm{~cm}$ above the valve ring. The aortic valves were heavily calcified with a small rigid orifice and a tricuspid structure. There was no evidence of other valve lesions, but the myocardium was flabby and had a grey appearance.

Bypass was set up and the aorta was opened obliquely. An aortic biopsy was taken and the edges of the incision were excised in an elliptical fashion in order to reduce the overall diameter. The wall of the aorta was normal, and did not have the features of Marfan's syndrome. The aortic valve was excised together with the extension of calcium into the valve ring.

In view of the possible difficulties with suturing and in the interests of speed a Starr prosthesis rather than a homograft was inserted. A size 10 silastic ball prosthesis was fixed in place with runs of continuous 2/0 Prolene, interrupted at several points. Rewarming was then carried out, and the aortotomy was closed with a double running whipstitch of 4/0 Prolene. A notable feature was the difficulty in closing the short ventriculotomy stab wound in the apex, since the myocardium was soft and friable and could not retain the sutures. It was eventually necessary to close the incision over two strips of Teflon felt with multiple interrupted stitches. The aorta was similarly dealt with on removal of the aortic cannula. Heart action remained good and in sinus rhythm throughout, and final closure was routine.

The patient's postoperative progress was excellent and uncomplicated. In particular no problem of haemostasis or wound dehiscence was encountered, and healing was not delayed. After normal convalescence he resumed work 3 months later, and follow-up after one year showed that he had remained fit and well.

\section{HISTOLOGY}

The biopsy of the aortic wall was examined independently by two pathologists, both of whom reported no microscopical abnormality in the 은 architecture of the collagen or elastic tissue. The hydroxyproline content of the aortic biopsy was assayed and found to be $6.4 \mathrm{mmol} / 1(84 \mathrm{mg} / 100 \mathrm{ml})$ (normal 0.6-3.7 mmol/1 (8-48 mg/100 ml)).

\section{Discussion}

Collagen is the most abundant protein in the human body, and in considering patients with Ehlers Danlos syndrome for surgery it is important to realise the great variability of the condition with $\overrightarrow{\bar{\theta}}$ respect to the type of connective tissue defect that may be present. Unlike Marfan's syndrome cardiac defects in Ehlers Danlos syndrome are infrequent and take no specific form (Beighton, 1970). The patient just described suffers fiom the type II or mild classic form of the disease, and this report is important in showing that aortic valve replacement is possible in this group when indicated.

It might have been expected on theoretical grounds that the sutures holding the prosthetic valve would tear out of the aortic ring, but this $\frac{D}{0}$ proved not to be the case, though the tissues did feel strangely soft to the needle. In contrast, $\widetilde{N}$ closure of the incision in the cardiac muscle for the $N$ apical bypass drain presented problems because of N the distinct friability of this tissue. The same prop- $O$ erty of the myocardium was reported by McFarland and Fuller (1964) in the case of a 17-year-old youth who died after spontaneous rupture of the right $\stackrel{\oplus}{\rightarrow}$ subclavian artery, and necropsy showed the liver, spleen, and bowel to be similarly affected. Their patient, however, had one of the more severe grades of the Ehlers Danlos syndrome.

Optimism over cardiac surgery may not, of course, be justified in the other variants of the syndrome, and especially in the more severe forms such as the 
ecchymotic and gravis types where spontaneous rupture of large arteries has often been reported (Mories, 1960; Barabas, 1967; Rybka and O'Hara, 1967). Angiography has also proved dangerous both because of bleeding at the site of the femoral puncture (Lynch et al., 1965) and from the catheter itself perforating the aortic wall (Schoolman and Kepes, 1967). The future for these patients lies in obtaining a clearer understanding of the biochemistry of collagen and its ultrastructure, with the hope that pharmacological control of its biosynthesis may be possible. Work along these lines using tissue cultures is already proceeding in some centres, but at present it is not possible to achieve results in animals or man without harmful side effects (Kivirikko and Risteli, 1976).

The authors thank Dr E. Olsen, The National Heart Hospital, London W1 for reviewing the histology of the aortic tissues.

\section{References}

Barabas, A. P. (1967). Heterogenity of the Ehlers-Danlos syndrome; description of three clinical types and a hypothesis to explain the basic defect(s). British Medical fournal, 2, 612-613.

Beighton, P. (1970). The Ehlers-Danlos Syndrome, p. 66. Heinemann Medical, London.

Di Ferrante, N., Leachman, R. D., Angelini, P., Donnelly, P. V., Francis, G., and Almazan, A. (1975). Lysyl oxidase deficiency in Ehlers-Danlos syndrome type IV. Connective Tissue Research, 3, 49-53.

Fantl, P., Morris, K. N., and Sawers, R. J. (1961). Repair of cardiac defect in a patient with Ehlers-Danlos syndrome and deficiency of Hageman factor. British Medical fournal, 1, 1202-1204.

Frieden, J., Hurwitt, E. S., and Leader, E. (1962). Ruptured aortic cusp associated with an heritable disorder of connective tissue. American Medical fournal, 33, 615-618.
Kivirikko, K. I., and Risteli, L. (1976). Biosynthesis of collagen and its alteration in pathological states. Medical Biology, 54, 159-186.

Lichtenstein, J. R., Martin, G. R., Kohn, L. D., Byers, P. H., and McKusick, V. A. (1973). Defect in conversion of procollagen to collagen in a form of Ehlers-Danlos syndrome. Science, 182, 298-300.

Lynch, H. T., Larsen, A. L., Wilson, R., and Magnusun, C. L. (1965). Ehlers-Danlos syndrome and 'congenital' arteriovenous fistulae. Fournal of the American Medical Association, 194, 1011-1014.

McFarland, W., and Fuller, D. E., (1964). Mortality in Ehlers-Danlos syndrome due to spontaneous rupture of large arteries. New England fournal of Medicine, 271, 13091310.

McKusick, V. A. (1972). Heritable Disorders of Connectiv'e Tissue, 4th ed. C. V. Mosby, Saint Louis.

McKusick, V. A. (1974). Multiple forms of the EhlersDanlos syndrome. Archives of Surgery, 109, 475-476.

Mories, A. (1960). Ehlers-Danlos syndrome, with a report of a fatal case. Scottish Medical fournal, 5, 269-272.

Pinnell, S. R., Krane, S. M., Kenzora, J. E., and Glimcher, M. J. (1972). A heritable disorder of connective tissue. Hydroxylysine deficient collagen disease. New England Fournal of Medicine, 286, 1013-1020.

Pope, F. M., Martin, G. R., Lichenstein, J. R., Penttinen, R., Gerson, B., Rowe, D. W., and McKusick, V. A. (1975). Patients with Ehlers-Danlos syndrome type IV lack type III collagen. Proceedings of the National Academy of Sciences of the United States of America, 72, 1314-1316.

Rybka, F. J., and O'Hara, E. T. (1967). Surgical significance of the Ehlers-Danlos syndrome. American fournal of Surgery, 113, 431-434.

Schoolman, A., and Kepes, J. J. (1967). Bilateral spontaneous carotid-cavernous fistulae in Ehlers-Danlos syndrome. fournal of Neurosurgery, 26, 82-86.

Sussman, M. D., Lichenstein, J. R., Nigra, T. P., Martin, G. R., and McKusick, V. A. (1974). Hydroxylysinedeficient skin collagen in a patient with a form of EhlersDanlos syndrome. Fournal of Bone and foint Surgery, 56A, 1228-1234.

Requests for reprints to Dr Philip Edmondson, 99 Harley Street, London W1N 1DF. 